Electrical supplementary information

\title{
High-Performance and Stable Hydrogen Evolution Reaction achieved by Pt trimer Decoration on Ultra-low Metal Loading Bimetallic PtPd Nanocatalysts
}

Dinesh Bhalothia, ${ }^{a}$ Tzu-Hsi Huang, ${ }^{\mathrm{b}}$ Chia-Wen Chang, ${ }^{\mathrm{b}}$ Ting-Han Lin, ${ }^{\mathrm{c}}$ Shun-Chi Wu, ${ }^{\mathrm{a}}$ KuanWen Wang,,$^{b^{*}}$ and Tsan-Yao Chena,c,d,e*

Affiliations:

a. Department of Engineering and System Science, National Tsing Hua University, Hsinchu 30013, Taiwan

b. Institute of Materials Science and Engineering, National Central University, Taoyuan City 32001, Taiwan

c. Institute of Nuclear Engineering and Science, National Tsing Hua University, Hsinchu 30013, Taiwan

d. Hierarchical Green-Energy Materials (Hi-GEM) Research Centre, National Cheng Kung University, Tainan 70101, Taiwan

e. Department of Materials Science and Engineering, National Taiwan University of Science and Technology, Taipei 10617, Taiwan

Corresponding Author(s):

Tsan-Yao Chen

Email: chencaeser@gmail.com

Tel: +886-3-5715131 \# 34271

FAX: +885-3-5720724 


\section{Benchmark of Pt-based catalysts in HER.}

Table S1. Comparison of HER activities of various low Pt loading catalysts.

\begin{tabular}{|c|c|c|c|c|c|}
\hline Samples & $\begin{array}{c}\text { Electrolyte, Scan } \\
\text { rate }\end{array}$ & $\begin{array}{c}\eta_{10} \\
(\mathbf{m V})\end{array}$ & $\begin{array}{l}\text { Tafel slope } \\
\text { (mV/dec) }\end{array}$ & $\begin{array}{c}\mathbf{M A}_{0.05} \\
\left(\mathbf{A} / \mathbf{m g}_{\mathrm{Pt}}\right)\end{array}$ & Reference \\
\hline Pt-NCs & & -53 & 32 & 1.3 & \\
\hline $\mathbf{P t}_{1} \mathbf{P d}_{2}-\mathrm{NCs}$ & $0.5 \mathrm{M} \mathrm{H}_{2} \mathrm{SO}_{4}, 2$ & -43 & 34 & 8.8 & \\
\hline $\mathrm{Pt}_{1} \mathrm{Pd}_{1}-\mathrm{NCs}$ & $\mathrm{mVs}^{-1}$ & -35 & 29 & 9.6 & This study. \\
\hline $\mathrm{Pt}_{2} \mathrm{Pd}_{1}-\mathrm{NCs}$ & & -25 & 32 & 5.7 & \\
\hline $\mathbf{P d}_{60} \mathrm{Pt}_{40}$ & $\begin{array}{c}0.5 \mathrm{M} \mathrm{H}_{2} \mathrm{SO}_{4}, 5 \\
\mathrm{mVs}^{-1}\end{array}$ & -130 & - & & 1 \\
\hline $\mathbf{P d}_{65} \mathbf{P t}_{35}$ & $\begin{array}{c}0.5 \mathrm{M} \mathrm{H}_{2} \mathrm{SO}_{4}, 50 \\
\mathrm{mVs}^{-1}\end{array}$ & N/A & 40 & $\begin{array}{c}4.98 \\
\text { (at }-300 \mathrm{mV} \text { ) } \\
\end{array}$ & 2 \\
\hline AuPd-NCs & $\begin{array}{c}0.5 \mathrm{M} \mathrm{H}_{2} \mathrm{SO}_{4}, 10 \\
\mathrm{mVs}^{-1}\end{array}$ & -29 & 47 & \multirow{2}{*}{$\mathrm{N} / \mathrm{A}$} & 3 \\
\hline PtRu-NCs & $\begin{array}{c}0.5 \mathrm{M} \mathrm{H}_{2} \mathrm{SO}_{4}, 100 \\
\mathrm{mVs}^{-1}\end{array}$ & $\begin{array}{c}-20 \\
\text { (IR Comp.) } \\
\end{array}$ & $\begin{array}{c}27 \\
\text { (IR Comp.) } \\
\end{array}$ & & 4 \\
\hline $\mathrm{Pt} / \mathrm{np}-\mathrm{Co}_{0.85} \mathrm{Se}$ & $\begin{array}{c}0.5 \mathrm{M} \mathrm{H}_{2} \mathrm{SO}_{4}, 50 \\
\mathrm{mVs}^{-1}\end{array}$ & -55 & 35 & $\begin{array}{c}1.32 \\
\text { (at }-100 \mathrm{mV})\end{array}$ & 5 \\
\hline $\mathbf{P t}_{1} / \mathbf{N P C}$ & $\begin{array}{c}0.5 \mathrm{M} \mathrm{H}_{2} \mathrm{SO}_{4}, 10 \\
\mathrm{mVs}^{-1}\end{array}$ & -25 & 28 & 2.86 & 6 \\
\hline Pt SASs/AG & $\begin{array}{c}0.5 \mathrm{M} \mathrm{H}_{2} \mathrm{SO}_{4}, 2 \\
\mathrm{mVs}^{-1}\end{array}$ & $\begin{array}{c}-12 \\
\text { (IR Comp.) }\end{array}$ & $\begin{array}{c}29 \\
\text { (IR Comp.) }\end{array}$ & $\begin{array}{c}22.4 \\
\text { (IR Comp.) }\end{array}$ & 7 \\
\hline Pt-MoS 2 & $\begin{array}{c}0.1 \mathrm{M} \mathrm{H}_{2} \mathrm{SO}_{4}, 2 \\
\mathrm{mVs}^{-1}\end{array}$ & -150 & 96.0 & \multirow{2}{*}{ N/A } & 8 \\
\hline $\mathrm{Pt} / \mathrm{MoS}_{2} / \mathrm{CFs}$ & $\begin{array}{c}0.5 \mathrm{M} \mathrm{H}_{2} \mathrm{SO}_{4}, 5 \\
\mathrm{mVs}^{-1}\end{array}$ & -80 & 53.6 & & 9 \\
\hline Pt@PCM & $0.5 \mathrm{M} \mathrm{H}_{2} \mathrm{SO}_{4}$ & -105 & 65.3 & \multirow{3}{*}{ N/A } & 10 \\
\hline $\mathbf{P t} / \mathbf{N i S} @ \mathbf{A l}_{2} \mathbf{O}_{3}$ & $\begin{array}{c}0.5 \mathrm{M} \mathrm{H}_{2} \mathrm{SO}_{4}, 5 \\
\mathrm{mVs}^{-1}\end{array}$ & -34 & 35.0 & & 11 \\
\hline $\mathrm{MO}_{2} \mathrm{TiC}_{2} \mathrm{~T}_{\mathrm{x}}-\mathrm{Pt}_{\mathrm{SA}}$ & $\begin{array}{c}0.5 \mathrm{M} \mathrm{H}_{2} \mathrm{SO}_{4}, 5 \\
\mathrm{mVs}^{-1}\end{array}$ & -30 & 30 & & 12 \\
\hline
\end{tabular}

$* \eta_{10}$ refers the overpotential at the cathodic current density of $10 \mathrm{mAcm}^{-2}$. 
2. XRD determined structure parameters and Fitting curves of experimental $\mathbf{P t}_{\mathbf{x}} \mathbf{P d}_{\mathbf{y}} \mathbf{N C s}$.
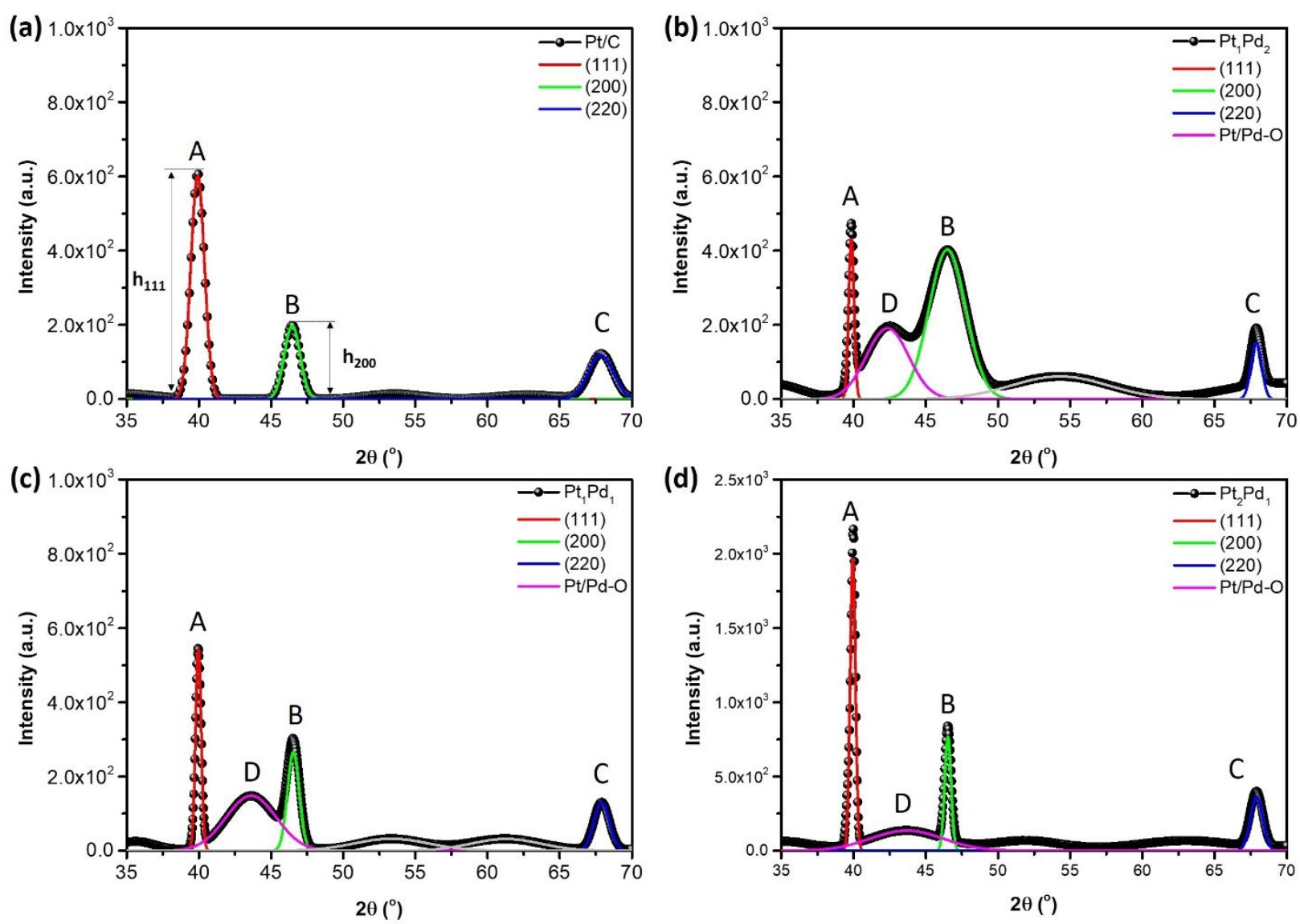

Figure S1. X-ray diffraction pattern and corresponding fitting curves of (a) Pt NC control sample, and experimental (b) $\mathrm{Pt}_{1} \mathrm{Pd}_{2}$, (c) $\mathrm{Pt}_{1} \mathrm{Pd}_{1}$, and (d) $\mathrm{Pt}_{2} \mathrm{Pd}_{1} \mathrm{NCs}$.

Table S2. XRD determined structure parameters of experimental $\mathrm{Pt}_{\mathrm{x}} \mathrm{Pd}_{\mathrm{y}} \mathrm{NCs}$ and reference sample Pt/C.

\begin{tabular}{|c|c|c|c|c|c|c|c|c|c|}
\hline \multirow{2}{*}{ sample } & \multicolumn{4}{|c|}{$\mathbf{d}_{(\mathrm{hkl})}(\AA)$} & \multirow{2}{*}{$\mathbf{H}_{(\mathbf{1 1 1})} / \mathbf{H}_{(\mathbf{2 0 0 )}}$} & \multicolumn{4}{|c|}{$\mathbf{D}_{(\mathbf{h k l})}(\AA) *$} \\
\hline & $\operatorname{Pt}(111)$ & $\operatorname{Pt}(200)$ & $\operatorname{Pt}(220)$ & PtPd-O & & $\operatorname{Pt}(111)$ & $\operatorname{Pt}(200)$ & $\operatorname{Pt}(220)$ & PtPd-O \\
\hline Pt & 2.257 & 1.952 & 1.380 & N/A & 3.0 & 76.05 & 67.4 & 47.4 & N/A \\
\hline $\mathbf{P t}_{1} \mathbf{P d}_{2}$ & 2.261 & 1.951 & 1.379 & 2.133 & 1.1 & 192.4 & 28.6 & 111.7 & 24.5 \\
\hline $\mathbf{P t}_{1} \mathbf{P d}_{1}$ & 2.254 & 1.949 & 1.379 & 2.073 & 2.1 & 184.1 & 89.2 & 76.1 & 20.8 \\
\hline $\mathbf{P t}_{\mathbf{2}} \mathbf{P d}_{\mathbf{1}}$ & 2.255 & 1.950 & 1.379 & 2.071 & 2.6 & 194.8 & 164.6 & 96.2 & 14.5 \\
\hline
\end{tabular}

$* \mathrm{D}_{(\mathrm{hkl})}$ : coherent length of (hkl) facet 
3. Fitting curves compared with experimental FT-EXAFS spectra at $P t L_{3}$-edge.
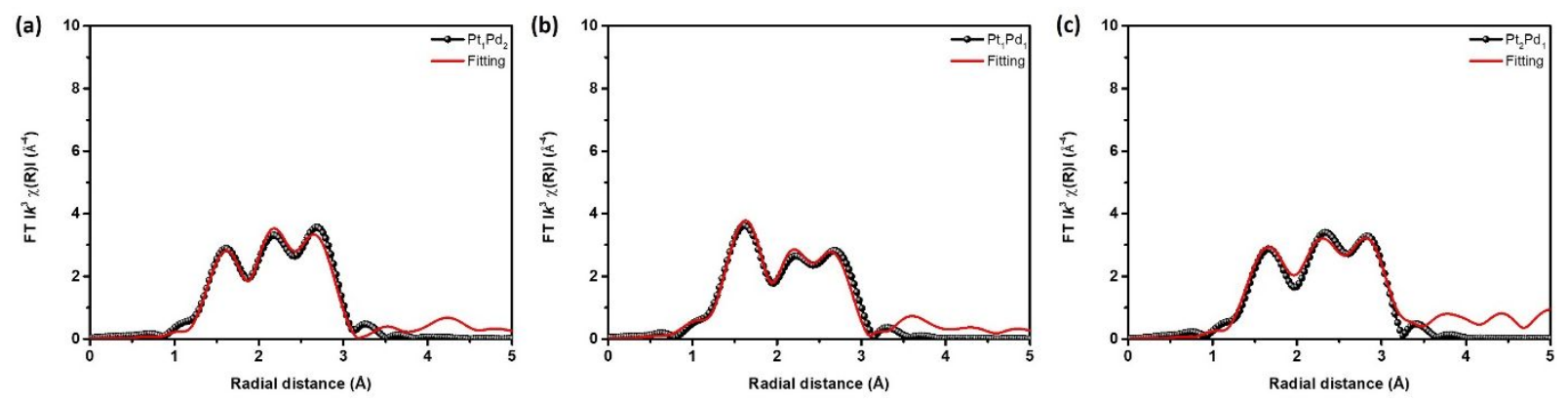

Figure S2. Model analysis fitting curves compared with experimental FT-EXAFS spectra at Pt $\mathrm{L}_{3}$-edge of (a) $\mathrm{Pt}_{1} \mathrm{Pd}_{2}$, (b) $\mathrm{Pt}_{1} \mathrm{Pd}_{1}$ and (c) $\mathrm{Pt}_{2} \mathrm{Pd}_{1} \mathrm{NCs}$. 
4. ICP-AES determined composition ratios of experimental NCs.

Table S3. ICP-AES determined composition ratios of experimental NCs.

\begin{tabular}{lllll}
\hline Samples & $\mathrm{Pt}($ wt. \%) & $\mathrm{Pd}($ wt. \%) & $\mathrm{Pt}($ at. \%) & $\mathrm{Pd}($ at. \%) \\
\hline $\mathrm{Pt} / \mathrm{C}$ & 2.8 & 0 & 100 & 0 \\
$\mathrm{Pt}_{1} \mathrm{Pd}_{2}$ & 0.9 & 0.8 & 37 & 63 \\
$\mathrm{Pt}_{1} \mathrm{Pd}_{1}$ & 1.2 & 0.6 & 53 & 47 \\
$\mathrm{Pt}_{2} \mathrm{Pd}_{1}$ & 2.7 & 0.8 & 66 & 34 \\
\hline
\end{tabular}




\section{CV curves of pristine and post CA experimental NCs}
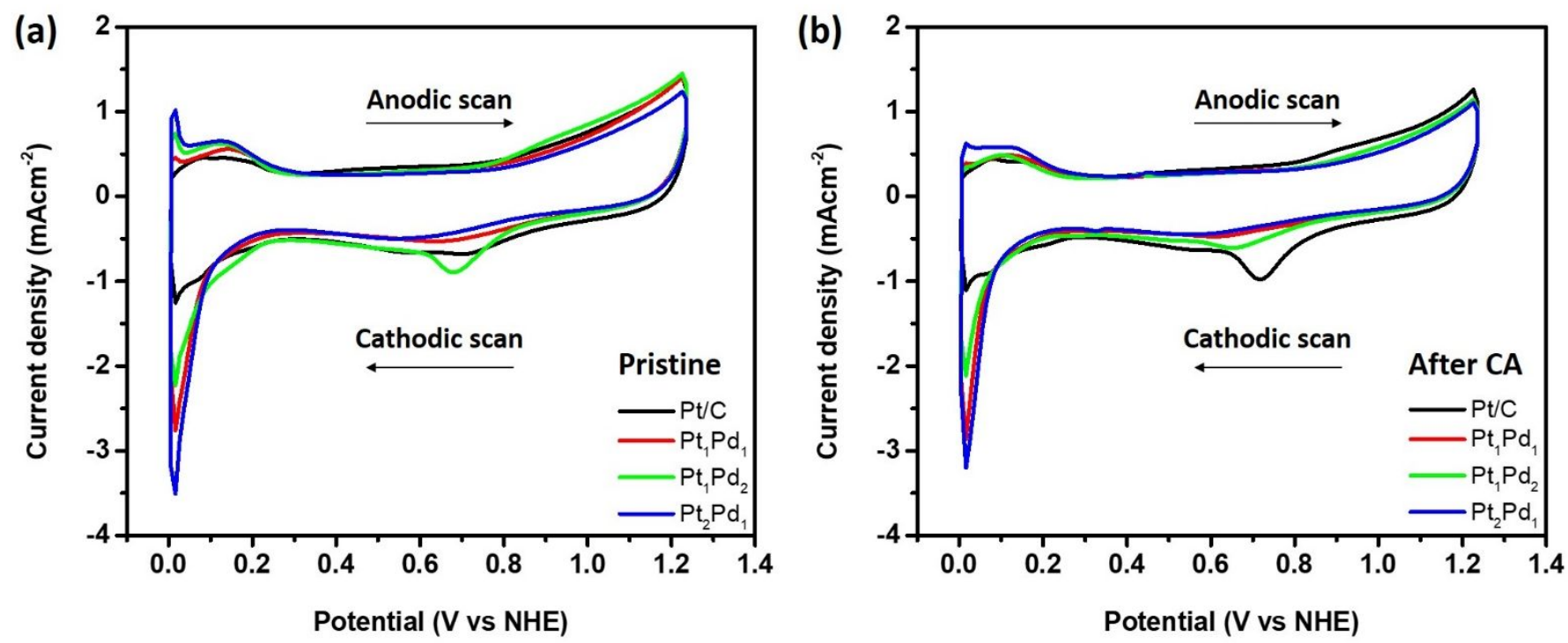

Figure S3. Comparative CV curves of experimental NCs (a) pristine and (b) Post CA.

\section{Turnover frequency (TOF) of experimental NCs}

Turnover frequency (TOF) is calculated using the following equation:

$\mathrm{TOF}=\left(\right.$ Current density $\left(A / \mathrm{cm}^{2}\right) \times$ geometry surface area $) /(2 \times F \times$ no. of moles of active catalyst )

where current density during the LSV measurement, and the geometrical surface area of $5 \mathrm{~nm}$ diameter ofRDE is $0.19625 \mathrm{~cm}^{2}$. F is the Faraday constant $\left(96485 \mathrm{C} \mathrm{mol}^{-1}\right)$ and the number of moles of active catalyst is calculated from the drop casted sample. ${ }^{13}$ 


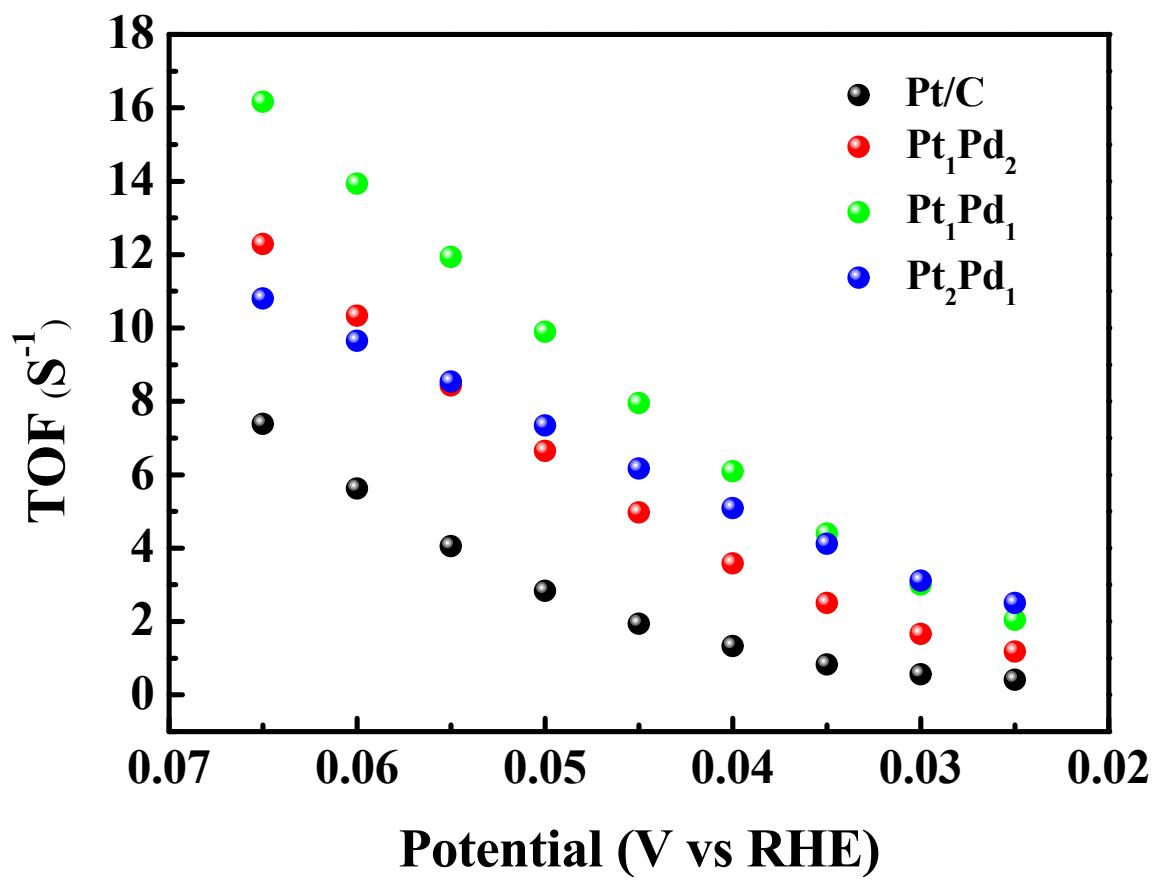

Figure S4. Turnover frequency of $\mathrm{Pt}_{\mathrm{x}} \mathrm{Pd}_{\mathrm{y}} \mathrm{NCs}$ compared with $\mathrm{Pt} / \mathrm{C}$. 


\section{The EIS analysis.}

In order to characterize the electrocatalytic activity of the $\mathrm{Pt}_{\mathrm{x}} \mathrm{Pd}_{\mathrm{y}} \mathrm{NCs}$, the EIS analysis was carried out at the overpotential of $50 \mathrm{mV}$. Figure $\mathbf{S 4}$ presents the comparative Nyquist plot of the experimental NCs and corresponding electrochemical impedance parameters (i.e. resistant from the electrolyte $\left(R_{u}\right)$, charge transfer-resistant on the electrode surface $\left(R_{c t}\right)$, resistant and capacitor that contributed by the carbon support $\left(\mathrm{R}_{\mathrm{N}}\right.$ and $\left.\mathrm{C}_{\mathrm{N}}\right)$, and capacitor that attributed by the electronic double layer $\left(\mathrm{C}_{\mathrm{dl}}\right)$ ) are listed in Table $\mathbf{S 4}$. The electrochemical impedance parameters are obtained by fitting the EIS curves via equivalent circuit diagram of the cathodic HER (Figure S5). ${ }^{14}$ The proposed equivalent circuit is composed by $\mathrm{R}_{\mathrm{u}}$ resistor series with two resistor-capacitor (RC) parallel circuits. The first and second $\mathrm{RC}$ parallel circuit are contributed by the carbon support and electron transfer process on the electrode, respectively. Some factors that may contribute to the circuit, are the mass-transfer of the electrode surface and electrolyte, the adsorption /desorption effect (Non-Faraday current), and the formation of the double-layer. ${ }^{15-16}$ In the Nyquist plot, the radius of the highfrequency semi-circle (smaller semicircle) is potential independent, which can be related to the electrode surface porosity response; the radius of the low-frequency semicircle (larger semicircle) is related to the charge transfer-resistant and double layer capacitance. ${ }^{17-18}$ It is evident from Figure $\mathbf{S} 4$ that the radius of the first and second semi-circle of the $\mathrm{Pt}_{1} \mathrm{Pd}_{1} \mathrm{NC}$ is smaller than those of $\mathrm{Pt}_{1} \mathrm{Pd}_{2}, \mathrm{Pt}_{2} \mathrm{Pd}_{1}$ and $\mathrm{Pt} / \mathrm{C} \mathrm{NCs}$, representing that the resistant from the mass transfer and electron transfer process is lowest, which is attributed to the presence of Pttrimers with more surface coverage and enhanced local structure ordering on Pd surface. Herein, it's worth to notice that the values of $R_{u}$ and $C_{N}$ of the $\mathrm{Pt}_{\mathrm{x}} \mathrm{Pd}_{\mathrm{y}}-\mathrm{NCs}$ are around 4.7 
ohm and $0.1 \mathrm{~F}$, respectively, indicating that those parameters are only dependent on the properties of the electrolyte and carbon support. The $\mathrm{Pt}_{1} \mathrm{Pd}_{1} \mathrm{NC}$ has the lowest $\mathrm{R}_{\mathrm{ct}}$ and maximum $\mathrm{C}_{\mathrm{dl}}$, suggesting the fastest charge transfer and adsorption/desorption process among experimental NCs. These results show that the decoration of high-density Pt-trimers on Pd surface can effectively promote the HER.

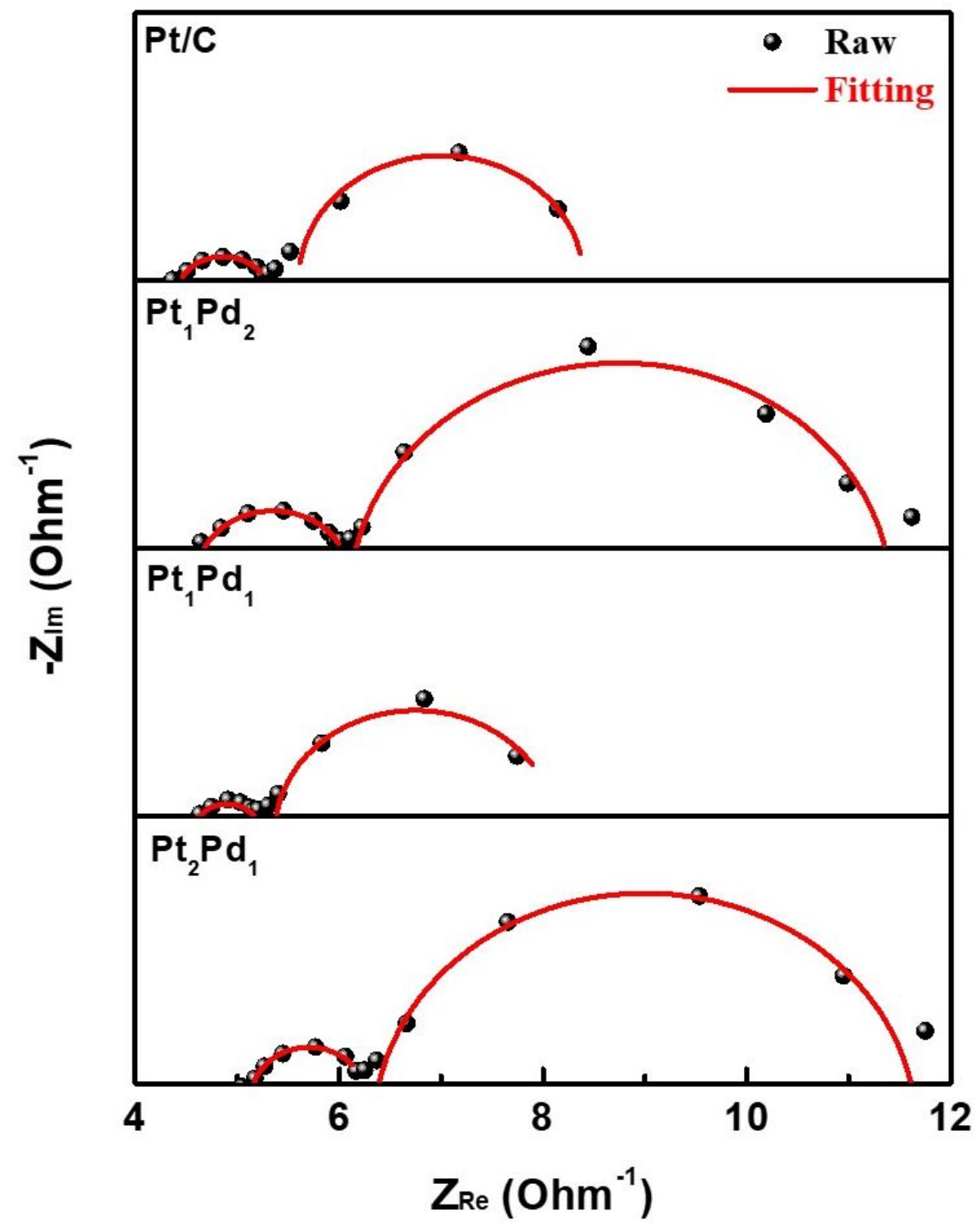

Figure S5. The Nyquist plot of the $\mathrm{Pt}_{\mathrm{x}} \mathrm{Pd}_{\mathrm{y}} \mathrm{NCs}$ compared with $\mathrm{Pt} / \mathrm{C} \mathrm{NC}$ 
Table S4. The electrochemical impedance parameters of the $\mathrm{Pt}_{\mathrm{x}} \mathrm{Pd}_{\mathrm{y}}$ and $\mathrm{Pt} / \mathrm{C} \mathrm{NCs}$.

\begin{tabular}{|c|c|c|c|c|c|}
\hline Samples & $\begin{array}{l}\mathrm{R}_{\mathrm{u}} \\
(\Omega)\end{array}$ & $\begin{array}{l}\mathrm{R}_{\mathrm{N}} \\
(\Omega)\end{array}$ & $\begin{array}{l}\mathrm{R}_{\mathrm{ct}} \\
(\Omega)\end{array}$ & $\begin{array}{l}\mathrm{C}_{\mathrm{N}} \\
(\mathrm{F})\end{array}$ & $\begin{array}{r}\mathrm{C}_{\mathrm{dl}} \\
(\mu \mathrm{F})\end{array}$ \\
\hline $\mathrm{Pt} / \mathrm{C}$ & 4.5 & 2.8 & 0.9 & 0.1 & 258 \\
\hline $\mathrm{Pt}_{1} \mathrm{Pd}_{2}$ & 4.7 & 3.4 & 1.3 & 0.1 & 121 \\
\hline $\mathrm{Pt}_{1} \mathrm{Pd}_{1}$ & 4.5 & 2.6 & 0.6 & 0.1 & 207 \\
\hline $\mathrm{Pt}_{2} \mathrm{Pd}_{1}$ & 5.0 & 3.5 & 1.0 & 0.1 & 171 \\
\hline $\begin{array}{l}\mathrm{R}_{\mathrm{u}}: \text { Resistant } \\
\mathrm{R}_{\mathrm{ct}}: \text { Charge tr } \\
\mathrm{R}_{\mathrm{N}}: \text { Resistant }\end{array}$ & $\begin{array}{l}\text { lectrc } \\
\text { istant } \\
\text { binde }\end{array}$ & urfac & \multicolumn{3}{|c|}{$\begin{array}{l}\mathrm{C}_{\mathrm{N}} \text { : Capacitor from the binder } \\
\mathrm{C}_{\mathrm{d} 1} \text { : Double-layer capacitor }\end{array}$} \\
\hline
\end{tabular}

8. The equivalent circuit diagram for the fitting of EIS curves.

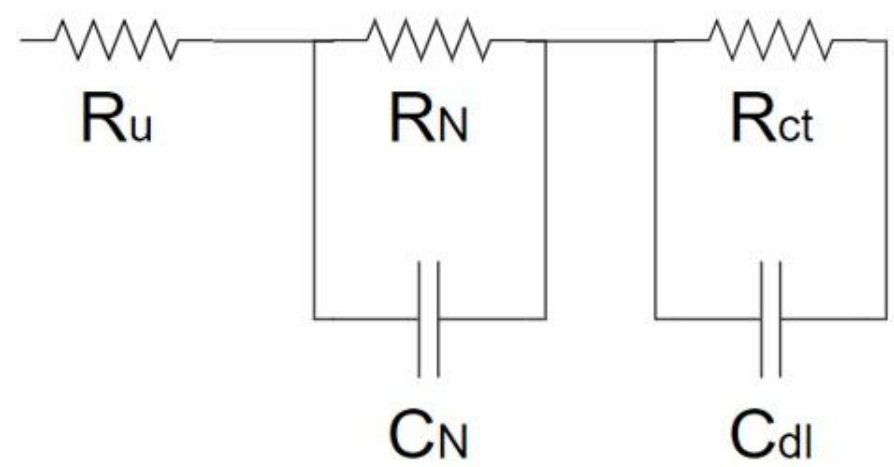

Figure S6. The equivalent circuit diagram of the cathodic HER. 


\section{References}

1. Ojani, R.; Raoof, J. B.; Hasheminejad, E., One-step electroless deposition of Pd/Pt bimetallic microstructures by galvanic replacement on copper substrate and investigation of its performance for the hydrogen evolution reaction. International Journal of Hydrogen Energy 2013, 38 (1), 92-99.

2. Rezaei, B.; Mokhtarianpour, M.; Ensafi, A. A., Fabricated of bimetallic Pd/Pt nanostructure deposited on copper nanofoam substrate by galvanic replacement as an effective electrocatalyst for hydrogen evolution reaction. International Journal of Hydrogen Energy 2015, 40 (21), 6754-6762.

3. Feng, J.-J.; Chen, L.-X.; Song, P.; Wu, X.-1.; Wang, A.-J.; Yuan, J., Bimetallic AuPd nanoclusters supported on graphitic carbon nitride: One-pot synthesis and enhanced electrocatalysis for oxygen reduction and hydrogen evolution. International Journal of Hydrogen Energy 2016, 41 (21), 8839-8846.

4. Li, K.; Li, Y.; Wang, Y.; Ge, J.; Liu, C.; Xing, W., Enhanced electrocatalytic performance for the hydrogen evolution reaction through surface enrichment of platinum nanoclusters alloying with ruthenium in situ embedded in carbon. Energy \& Environmental Science 2018, $11(5), 1232-1239$.

5. Jiang, K.; Liu, B.; Luo, M.; Ning, S.; Peng, M.; Zhao, Y.; Lu, Y.-R.; Chan, T.-S.; de Groot, F. M. F.; Tan, Y., Single platinum atoms embedded in nanoporous cobalt selenide as electrocatalyst for accelerating hydrogen evolution reaction. Nature Communications 2019, $10(1), 1743$.

6. Li, T.; Liu, J.; Song, Y.; Wang, F., Photochemical Solid-Phase Synthesis of Platinum Single Atoms on Nitrogen-Doped Carbon with High Loading as Bifunctional Catalysts for Hydrogen Evolution and Oxygen Reduction Reactions. ACS Catalysis 2018, 8 (9), 84508458 .

7. Ye, S.; Luo, F.; Zhang, Q.; Zhang, P.; Xu, T.; Wang, Q.; He, D.; Guo, L.; Zhang, Y.; He, C.; Ouyang, X.; Gu, M.; Liu, J.; Sun, X., Highly stable single Pt atomic sites anchored on aniline-stacked graphene for hydrogen evolution reaction. Energy \& Environmental Science 2019, 12 (3), 1000-1007.

8. Deng, J.; Li, H.; Xiao, J.; Tu, Y.; Deng, D.; Yang, H.; Tian, H.; Li, J.; Ren, P.; Bao, X., Triggering the electrocatalytic hydrogen evolution activity of the inert two-dimensional MoS2 surface via single-atom metal doping. Energy \& Environmental Science 2015, 8 (5), 1594-1601.

9. Hou, D.; Zhou, W.; Liu, X.; Zhou, K.; Xie, J.; Li, G.; Chen, S., Pt nanoparticles/MoS2 nanosheets/carbon fibers as efficient catalyst for the hydrogen evolution reaction. 
Electrochimica Acta 2015, 166, 26-31.

10. Zhang, H.; An, P.; Zhou, W.; Guan, B. Y.; Zhang, P.; Dong, J.; Lou, X. W., Dynamic traction of lattice-confined platinum atoms into mesoporous carbon matrix for hydrogen evolution reaction. Science Advances 2018, 4 (1), eaao6657.

11. Feng, Y.; Guan, Y.; Zhang, H.; Huang, Z.; Li, J.; Jiang, Z.; Gu, X.; Wang, Y., Selectively anchoring Pt single atoms at hetero-interfaces of $\gamma$-A12O3/NiS to promote the hydrogen evolution reaction. Journal of Materials Chemistry A 2018, 6 (25), 11783-11789.

12. Zhang, J.; Zhao, Y.; Guo, X.; Chen, C.; Dong, C.-L.; Liu, R.-S.; Han, C.-P.; Li, Y.; Gogotsi, Y.; Wang, G., Single platinum atoms immobilized on an MXene as an efficient catalyst for the hydrogen evolution reaction. Nature Catalysis 2018, 1 (12), 985-992.

13. Li, D.; Fang, H.; Yu, J.; Xu, M.; Li, T.; Wang, J., Porous carbon supported PtPd alloy nanoparticles derived from $\mathrm{N}$-heterocyclic carbene bimetal complex as efficient bifunctional electrocatalysts. Electrochimica Acta 2020, 337, 135855.

14. Heusler, K. E., E. Gileadi; electrode kinetics for chemists, chemical engineers and material scientists. VCH, Weinheim, New York, Basel, Cambridge, Tokyo 1993, ISBN 3-527-895612, 597 S., Preis: DM 189. Berichte der Bunsengesellschaft für physikalische Chemie 1994, 98 (4), 644-645.

15. Domínguez-Crespo, M. A.; Ramírez-Meneses, E.; Torres-Huerta, A. M.; Garibay-Febles, V.; Philippot, K., Kinetics of hydrogen evolution reaction on stabilized Ni, Pt and Ni-Pt nanoparticles obtained by an organometallic approach. International Journal of Hydrogen Energy 2012, 37 (6), 4798-4811.

16. Harrington, D. A.; Conway, B. E., ac Impedance of Faradaic reactions involving electrosorbed intermediates-I. Kinetic theory. Electrochimica Acta 1987, 32 (12), 17031712 .

17. Łosiewicz, B.; Budniok, A.; Rówiński, E.; Łągiewka, E.; Lasia, A., The structure, morphology and electrochemical impedance study of the hydrogen evolution reaction on the modified nickel electrodes. International Journal of Hydrogen Energy 2004, 29 (2), 145-157.

18. Królikowski, A.; Wiecko, A., Impedance studies of hydrogen evolution on Ni $\square \mathrm{P}$ alloys. Electrochimica Acta 2002, 47 (13), 2065-2069. 